\title{
Privatizations in Developing Countries and the Government's Budget Constraint
}

\author{
Emmanuelle Auriol* \\ Pierre M. Picard ${ }^{\dagger}$ \\ University of Toulouse I University of Manchester
}

May 11, 2004

\begin{abstract}
We study the impact of government's budget constraint on the privatization decision of increasing returns to scale industry. Privatization is associated with prices liberalization, public ownership with regulation. Under public ownership the governments balance the benefits of taxing profitable public firms with the cost of soft-budget constraint. Privatization hardens the firms budget constraint, but yields prices distortion. With natural monopoly privatization is preferred to regulation for intermediate values of the shadow cost of public funds. On the other hand with natural duopoly regulated competition is always preferred to privatization.
\end{abstract}

${ }^{*}$ Correspondence: Emmanuelle Auriol: ARQADE and IDEI Université de Toulouse I, Place AnatoleFrance, 31042 Toulouse cedex, France. E-mail: eauriol@cict.fr

${ }^{\dagger}$ University of Manchester, School of Economic Studies, Oxford Road, Manchester MP13 9PL. E-mail: Pierre.Picard@man.ac.uk. 


\section{Introduction}

Between 1980 and 1996, state ownership in low income countries went from $16 \%$ to $8 \%$ of GDP (Megginson and Netter (2001)). As a result, the proceeds of privatization in non-OECD countries account for about $\$ 50$ billion per year, no less than one third of the worldwide proceeds of privatization (Mahboobi, 2000; Gibbon, 1998, 2000). In most of the cases governments privatized public assets because of critical budgetary conditions. ${ }^{1}$ International donors and creditors, like the World Bank or the IMF, made privatization programs a condition for economic assistance in the 1980's context of explosive debt crisis. Privatizations have been a major component of structural adjustment programs. Using a panel of 18 developing countries, Davis et al. (2000) show that budgetary privatization proceeds have been used to reduce domestic financing on a roughly one-for-one basis. The paper studies the impact of poor budgetary conditions on the privatization decisions of infrastructure industries and public utilities.

Market failures arise in markets with natural monopolies (i.e. firms with large economies of scale). ${ }^{2}$ According to Walras (1936), a legal monopoly should be set to prevent wasteful duplication of investments, and should be regulated to avoid the welfare loss associated to monopoly pricing. This argument has generally led governments in developing countries to control markets and production through public ownership. As a result they assumed responsibility for the firm's profits and losses. The possibility to transfer resources between the government and public firms generates a soft-budget constraint (Kornai 1980). Under incomplete information, the government can hardly discriminate between good and bad project and/or management. Ex-post, governments are likely to transfer too much resources to firms (through subsidies or through soft bank credit and trade credit). Kornai (2001) provides evidence of the use of soft-budget constraints by state-owned enterprises

\footnotetext{
${ }^{1}$ This has also been the case in rich countries. For instance, the first Japanese privatization were initiated in 1982 when the Japanese public deficit reached 41.2\% of GDP. Similarly in the U.S. Lopezde-Silanes et al. (1997) show that, privatizations have been more likely in States where fiscal constraints were more binding.

${ }^{2}$ Empirical studies reveal that privatization results in lower prices and higher output in competitive industries but not in natural monopolies. Changing the ownership structure does not solve for the lack of competitive pressure (see Nellis (1999)).
} 
(SOEs) in developing countries.

Privatization hardens the budget constraint. Because managers and/or owners of privatized firms assume the responsibility for the firm's cash flows, the government is not constrained to transfer resources to money loosing firms. There has hence been a substantial decrease of government subsidies to formally SOEs following the reforms. For instance the privatisation commission of Burkina Faso, reports that government subsidies to SOEs went from 1.42 percent of GDP in 1991 to 0.08 percent of GDP in 1999 as a result of privatisation (OECD-BAD 2003). However, the hardening of the budget constraint has a cost. On the one hand, the government is not able to take advantage of the positive cash flows in profitable firms. On the other hand, it abandons the direct control of firm's operations which has a cost to consumers. In particular empirical evidence shows that the output prices of natural monopolies increased as a result of privatization : "Steep price increases following privatization have been quite common in divested network or infrastructure industries, e.g. electricity and water and sewerage, and common but not universal in telecommunications." Birdsall-Nellis (2002). ${ }^{3}$ An unaccounted part of price increases stems from the termination of illegal connections (Birdsall-Nellis 2002, Estache et al 2002, OECD-BAD 2003).

The question addressed in this paper is whether the elimination of soft-budget constraint together with the cash-flow generated by privatization compensate for the price distortion associated with private monopoly and oligopoly. Privatization is not equivalent to laissez-faire because entry remains regulated (i.e., through licence and entry fees). Nevertheless it here is treated as the move from public ownership with regulation of entry and price to private ownership with price liberalization. This assumption is somewhat extreme. One could reasonably argue in favor of a solution where privatization is associated with some kind of price regulation, in addition to the regulation of entry. The first justification is theoretical. Under the complete contract approach adopted in the paper there is no difference between public ownership and private ownership under regulation

\footnotetext{
${ }^{3}$ Prices are sometimes increased ahead of privatization in order to reduce the SOEs financing gaps and attract buyers. This has been for instance the case for electricity tariffs in Zimbabwe, in Kenya and in Senegal, that the government increased by $10 \%$ after reaching an agreement with Vivendi Universal (see OECD-BAD 2003).
} 
of entry and price. We thus model the difference between the two structures as a choice between public regulated firms and private price unregulated ones. The second argument is empirical. As stressed in Estache, Foster and Wodon (2002), in privatization reforms governments have the choice between auctioning off the operator on the basis of the highest royalty payment, or waiving the royalty payment and auctioning off the service to the party who bids the lowest service tariff. Guasch (2000) shows in a recent survey of 600 concession contracts from around the world that in most cases contracts are tendered for the highest transfer or annual fee. Since in practice governments in developing countries are more concerned with relieving fiscal constraint than securing tariff reductions, the concession contracts show a move towards prices liberalization.

The paper focuses on the impact of the opportunity cost of public funds on the privatization decision. It shows that privatization of natural monopolies can be optimal because of the tightness of the government budget constraint. ${ }^{4}$ This result is not obvious because a benevolent regulation should be able, at worse, to mimic the private monopoly outcome. This is at least what the revelation principle suggests. However because of the soft-budget constraint in SOEs (and not in private structures), this intuition turns out to be false. When public finance matters, privatization can dominate a benevolent regulation. To illustrate this result consider the limit case where the government cannot finance an infrastructure (e.g., a road). Privatization is an appealing alternative to the absence of public funds. It is indeed better to have a privately owned and operated infrastructure, even with the monopoly distortion (e.g., a toll), than no infrastructure at all. By continuity the result still holds when the government is able to finance the infrastructure. We hence show that when the profitability of the industry is low, the optimal industrial policy is monotone in the shadow cost of public funds. For the low shadow costs regulation dominates privatization, and it is the reverse for the large shadow costs.

The next result is a consequence of the difficulty met by developing countries to attract investors while auctioning off their profitable SOEs. ${ }^{5}$ Empirical studies hence show that

\footnotetext{
${ }^{4}$ As in Laffont \& Tirole (1993), we assume that the shadow cost of public funds summarizes the tightness of this constraint, larger shadow costs of public funds stemming from tighter budget constraint.

${ }^{5}$ Country risk analysis is very important in today's global investment strategies because it is the basis of determining future expected returns of investment. Since the perception of business risk tends to be
} 
SOEs are generally sold at a discount (see Birdsall-Nellis 2002). With underpriced public assets, the optimal policy is non monotone in the shadow cost of public funds. When the shadow cost of public funds is low, the government set prices close to marginal cost and subsidizes the regulated firm to cover the fixed cost. Rises in the shadow cost of public funds increase the social cost of such transfers. The government prefers to let a private firm take over for intermediate values. Finally for very large values the government which focuses exclusively on revenue, prefers to keep profitable firms public rather than to sell them off. Prices are set close to the private monopoly level in order to maximize profit and thus government revenue. Then for very low values of the shadow cost (i.e., when bailouts are cheap) or very large values (i.e. when 'holdup' on profitable industries are valuable) regulation is preferred to privatization. It is the reverse for intermediate value. This non-monotonicity result has potential important policy implications. That is, while divestiture of profitable public firms may be optimal in developed countries, it is not necessarily optimal in developing countries where budget constraint is tight and market institutions are weak.

Finally, when ex-ante profitability rises substantially, the market allows the entry of more than one firm. The paper then shows that the advantage of private structures is likely to disappear. Indeed, when a second firm is introduced, the cost of information and soft-budget constraint in regulated firms diminish more than the cost of excessive prices and entry in private oligopolies. In other words, market liberalization, which corresponds to the divestiture of an historical monopoly and the introduction of new entrants, is not equivalent to laissez-faire. In the framework of our model the divestiture of the historical monopoly is motivated by smaller fixed costs and/or by larger product demand. The telecommunication industry provides a good illustration of these changes. The paper then suggests that privatization cannot succeed without an effective regulation of entry and prices. The experience in industrialized countries shows that regulation of access pricing to bottleneck facilities (i.e., fixed distribution network) is a key component of successful liberalization reforms. This is a major concern in developing countries. They higher in poor countries, this affects negatively the supply and cost of international capital flows for these countries. 
usually lack the human ressources and the institutions for creating a credible regulatory authority. $^{6}$

\subsection{Relationship with the literature}

The critical problem induced by soft-bugdet constraints has firstly been coined by Kornai's (1980) as the lack of government commitment not to bail out or subsidize moneylosing firms: ${ }^{7}$ "The softening of the budget constraint appears when the strict relationship between expenditure and earnings of an economic unit (firms, household, etc) has been relaxed, because expenditure will be paid by some other institutions, typically the paternalistic state." (Kornai 1980). The author shows that soft-budget constraints explained many inefficiencies occurring in socialist economies such as shortages or low price responsiveness. Transfers of public ownership to private ownership has hence often been grounded on the poor economic performance of public enterprises. Since less efficient firms were allowed to rely on the government for funding, they lacked the financial discipline required for efficient management (Dewatripont and Maskin (1995) and Schmidt (1996a, 1996b)). In Dewattripont and Maskin (1995) and Maskin (1999) the soft-budget constraint is caused by the contract incompleteness between governments and firms. ${ }^{8}$ On the other hand when governments are able to offer the same contracts to public and to private firms, for instance in the form of bribes to private firms as in Kornai (2001) and Schmidt (1996), both structures have the same degree of contract completeness and private or public ownership is irrelevant. ${ }^{9}$

\footnotetext{
${ }^{6} \mathrm{~A}$ major concern with privatization reforms in developing countries is government commitment ability. For instance, according to a World Bank database on Latin America, the concessions that were granted to private operators following the divestiture of public firms have been renegotiated after an average 2.1 years only (see Laffont 2001 and Guash-Laffont-Straub 2002).

${ }^{7}$ Interesting surveys are available in Kornai (2000), Kornai, Maskin and Roland (2002) and Glaeser and Shleifer (2003).

${ }^{8}$ In these two papers soft budget constraints affect the level of uncontractable investments made in firms by managers. By hardening the firm's budget constraint, privatization helps restoring appropriate investment incentives and it improves production efficiency.

${ }^{9}$ Williamson (1985) and Grossman and Hart (1986) shown that control rights are what matters to define ownership and that the ownership structure does not matter if complete contracts can be written.
} 
To be in line with the regulation literature we adopt in this paper a complete contract approach (see Laffont-Tirole 1993). This implies that under regulation the ownership structure is irrelevant. We then draw the line between private and public structures by assuming that privatization leaves control and cash-flow rights to private interests. ${ }^{10} \mathrm{On}$ the other hand under regulation, governments control the firm's outputs (prices, quantities and cash-flow) and firms' managers control the firm's input mix (technology, effort, labor, ...). This leads to incentives problem (i.e., adverse selection). Indeed regulation is constrained by informational asymmetries between governments and managers. To overcome the asymmetry of information the government offers a menu of revealing contracts to the regulated firm. To avoid the threat of service interruption it sets the contracts so that the least productive type of firm breaks even. This implies that the other types of firm make informational rents. Production is distorted to reduce the cost of these rents (see Laffont and Tirole 1993). This negative effect of soft-budget constraint on the allocative efficiency of the firm is different from the negative effect on productive efficiency illuminated by the pioneer papers on privatization. In contrast the paper simply avoids moral hazard issues. It is a contribution in regulation theory with adverse selection that considers an alternative to the regulatory regime, namely, privatization with price liberalization.

Finally soft-budget constraints have often been theoretically associated to a lack of economic orientation in governments' objectives. For instance in Kornai and Weibull (1983), Shleifer and Vishny (1996), Debande and Friebel (2003), governments have 'parternalistic' or political behavior as they seek to protect or increase employment; in Shapiro and Willig (1990), governments are simply malevolent. In contrast in this paper we assume, as in Laffont and Tirole (1993), in Schmidt (1996a and 1996b) or in Segal (1998) that government is utilitarian. It maximizes some mix of consumption and production surpluses. The soft-budget constraint does not stem from the lack of government's economic orientation. It is just a consequence of public ownership.

\footnotetext{
${ }^{10}$ Shleifer and Vishny (1994) have demonstrated that the allocation of control right leads to economic efficiency when control rights are congruent to cash flows rights (see definition of the latter rights in Shleifer and Vishny, 1994 or in Roland 2000).
} 
The paper is organized as follows. Section 2 presents the model and the main assumptions. Section 3 compares the performance of private and regulated monopolies while Section 4 studies the duopoly case. Section 5 derives the optimal industrial policy. Section 6 summarizes our results and offers some concluding remarks.

\section{The model}

We consider a problem of industrial policy setting. The government has to decide whether an industry characterized by increasing returns to scale should be under public or private control. In line with Laffont and Tirole (1993), we call regulation regime the regime in which the government controls the production of a regulated firm. The government's control rights are associated with accountability on profits and losses. That is, it must subsidize the firm in case of losses whereas it taxes the firm in case of profits. Concretely, in the context of a developing country, this corresponds to public ownership.

In contrast, we call private regime the regime in which the government imposes no control on the operations of a private firm, and it takes no responsibility for the firm's profits or losses. That is, no transfer is possible between the government and the private firm once production has begun. This is of course a simplification. In practice government might transfer some funds to the private sector. However subsidies are lower under privatization than under public ownership. We normalize without any loss of generality them to zero under public ownership. More particularly, private firms do not pay tax on profit but they pay an entry fee. This is an artifact of the formalization. In the static model below it is optimal for the government to sell the firm ex-ante (i.e., while it is in a position of symmetric information vis à vis the firm) rather than to tax its profit ex-post (i.e., once the firm has learned its cost parameter and has an informational advantage). The empirical evidences also show that developing countries rely on market entry fees to raise revenues from firms (see Auriol-Walters (2003)). They are paid up front and do not require follow up. Entry fees fill two purposes: as a tax instrument they have low administrative costs, as a barrier to market entry they are a convenient tool of government's industrial policy. 
To keep the analysis simple we consider a linear product demand. However the results are robust to more general demand function (e.g., CES functions). The inverse demand function for $Q \geq 0$ units of the commodity is given by

$$
P(Q)=a-b Q
$$

where $a>0$ and $b>0$ are common knowledge. The gross consumer surplus is therefore

$$
S(Q)=\int_{0}^{Q} P(x) d x=a Q-\frac{b}{2} Q^{2} .
$$

On the production side there are $N$ firms in the industry. Firm $i \in\{1, \ldots, N\}$ produces output $q_{i}$. The total production in the industry is $Q=\sum_{i=1}^{N} q_{i}$. Firm $i \in\{1, \ldots, N\}$ has the following cost function:

$$
C\left(\beta_{i}, q_{i}, K\right)=K+\beta_{i} q_{i}
$$

As in Baron-Myerson (1982), the cost function includes a fixed cost $K>0$, and an idiosyncratic marginal cost $\beta_{i}$. Firm $i$ must make the investment $K$ before discovering $\beta_{i}$. Neither the government nor the competitors of firm $i$ observe this firm-specific cost parameter. The parameter $\beta_{i}$ is independently drawn from the support $[\underline{\beta}, \bar{\beta}]$ according to the density and cumulative distribution functions $g(\cdot)$ and $G(\cdot)$. This law is common knowledge. We denote the expectation operator by $E$, the average marginal cost by $E \beta$, and the variance of marginal cost by $\sigma^{2}=\operatorname{var}(\beta)$.

We focus on increasing return to scale industries. The fixed cost $K$ is large so that the maximal number of firms $N$ that can survive under laissez-faire is small. To be more specific we make the following assumption:

A0

$$
K \geq \frac{(a-E \beta)^{2}}{16 b}+\frac{\sigma^{2}}{4 b}
$$

Assumption A0 implies that $N \in\{0,1,2\} .{ }^{11}$

The firms are profit maximizer. The profit of firm $i$ is

$$
\Pi_{i}=P(Q) q_{i}-C\left(\beta_{i}, q_{i}, K\right)+t_{i}
$$

where $t_{i}$ is the net transfer that the firm gets from the government (subsidy minus tax and franchise fee).

\footnotetext{
${ }^{11}$ To find out how condition A0 is computed see section 4.1 footnote 21.
} 
The government is utilitarian and maximizes the sum of consumer and producer surpluses minus the social cost of transferring public funds to the firm(s). The transfer to the firm(s) can either be positive (i.e., a subsidy), or negative (i.e., a tax). The government's objective function is

$$
W=S(Q)-\sum_{i=1}^{N} C\left(\beta_{i}, q_{i}, K\right)-\lambda \sum_{i=1}^{N} t_{i}
$$

where $\lambda$ is the shadow cost of public funds. ${ }^{12}$

The shadow cost of public funds, $\lambda$, drives the results of the paper. This shadow cost, which can be interpreted as the Lagrange multiplier of the government budget constraint, measures the social cost of the government's economic intervention. For $\lambda$ close to 0, the government maximizes the net consumers' surplus; for larger $\lambda$, the government puts more weight on transfers. The shadow cost of public funds is positive because transfers to regulated firms imply either a decrease in the production of public goods, such as schooling and health care, or an increase in distortionary taxation. Each dollar that is transferred to the regulated firm costs $1+\lambda$ dollars to society. In developed economies, $\lambda$ is mainly equal to the deadweight loss accrued to imperfect income taxation. It is assessed to be around 0.3 (Snower \& Warren, 1996). In developing countries, low income levels and difficulties in implementing effective taxation programs are strong constraints on the government's budget, which leads to higher values of $\lambda$. As a benchmark case the World Bank (1998) suggests a shadow cost of 0.9. The value is much higher in countries that are heavily indebted.

\section{Private versus regulated monopoly}

When $K$ is large, a natural monopoly emerges: $N \in\{0,1\}$. Since there is at most one firm, the firm index $i$ can be temporarily dropped. The production of the monopoly is equal to the total production $Q$. Regulation aims at correcting the distortion associated with monopoly pricing in the laissez-faire situation. Theory in regulation suggests that,

\footnotetext{
${ }^{12}$ The analysis and the results of the paper are consistent with a less optimistic view of government objectives. It is just a matter of interpretation of $\lambda$. With a non benevolent government, $\lambda$ is the weight the government puts on the transfers it can get out of the firms (e.g., bribes).
} 
at worse, a benevolent regulator should be able to mimic the choice of a private firm. Although regulation always dominates privatization under complete information, we show that it is not always the case under asymmetric information.

\subsection{Private monopoly}

The production levels of private monopolies (henceforth $P M$ ) are not controlled by the government. The government can nevertheless control the entry of private monopolies by auctioning the right to operate. Let $F(\lambda) \geq 0$ be the franchise fee that the private firm pays to the government in order to operate in the product market. The private monopoly contemplates the following sequential choices. First, the monopoly chooses to enter the market by paying the franchise fee $F(\lambda)$ and by making the investment $K$. If it enters, then nature chooses the marginal cost $\beta$ according to the distribution $G(\cdot)$. The private firm learns $\beta$ and chooses a production level $Q$. After the realization of $\beta$ the private firm never pays or receives a transfer from the government.

The profit of the private monopoly is

$$
\Pi^{P M}=\max _{Q} P(Q) Q-C(\beta, Q, K)-F(\lambda)
$$

The optimal production is independent of $K$ and $F(\lambda)$ :

$$
Q^{P M}=\frac{a-\beta}{2 b}
$$

If $a$ is smaller than the firm's marginal $\operatorname{cost} \beta$, the production level falls to 0 . In order to rule out corner solution in the sequel of the paper, we assume that $a$ is not too small:

$$
\text { A1 } \quad a \geq \max \left\{2 \bar{\beta}, \bar{\beta}+\frac{G(\bar{\beta})}{g(\bar{\beta})}\right\} .
$$

Substituting $Q^{P M}$ in equations (4) and (5), we get the ex-ante profit and welfare of a private monopoly,

$$
\begin{aligned}
E \Pi^{P M} & =\frac{1}{2} V-K-F(\lambda), \\
E W^{P M}(\lambda) & =\frac{3}{4} V-K+\lambda F(\lambda)
\end{aligned}
$$


where

$$
V=\frac{E(a-\beta)^{2}}{2 b}
$$

The value of operating the firm after the investment is made is measured by $V .{ }^{13} \mathrm{~A}$ monopoly is privately feasible if it is ex-ante profitable, i.e. if $E \Pi^{P M} \geq 0$. This requires $\frac{1}{2} V \geq K$ and $F(\lambda) \in\left[0, \frac{1}{2} V-K\right]$. Similarly a monopoly is socially valuable if it brings exante positive welfare, i.e. if $E W^{P M} \geq 0$. It is easy to check that monopolies are socially valuable but privately infeasible if $\frac{3}{4} V>K>\frac{1}{2} V$. Because of the government need for cash, the ex-ante welfare $E W^{P M}(\lambda)$ increases linearly with $F(\lambda)$. The maximal entry fee that the government can collect is the maximum price a risk neutral entrepreneur would agree to pay for the monopoly concession:

$$
F^{*} \equiv \max \left\{0, \frac{1}{2} V-K\right\}
$$

In practice international capital flows depend on country risk ratings so that government of developing countries do not collect $F^{*}$ (see Brewer and Rivoli 1990). Because of the service of their debt, the perception of corruption in the administration and the social instability, the lack of transparency and predictability of their political and judicial institutions, developing countries get bad ratings. ${ }^{14}$ A consequence of the bad ratings is that private investors, especially foreign ones, are very reluctant to invest in these countries. For instance in 1999 foreign direct investment (FDI) inflows to the 49 least develop countries (roughly $10 \%$ of the world population) was $0.5 \%$ of total world FDI flows. Since less than $10 \%$ of this investment was cross-border merger and acquisition (including privatization), privatization proceeds are dismally low in poor countries, despite sometimes a

\footnotetext{
${ }^{13}$ One can check that $V=\frac{(a-E \beta)^{2}}{2 b}+\frac{\sigma^{2}}{2 b}$. It can be separated into two components: the value at the average cost, $(a-E \beta)^{2} / 2 b$, and the value of the cost spread, $\sigma^{2} / 2 b$.

${ }^{14}$ The ratings combine a range of qualitative and quantitative information. They reflect the ability and willingness of a country to service its financial obligation. There are five different measures of country risk: political risk, financial risk, economic risk, composite risk indices and institutional investor's country credit ratings. The leading rating agencies are Standard and Poor's, Moody's, Euromoney, Institutional Investor, Economist Intelligence Unit, International Country Risk Guide. See for instance Global Risk Assessments web site, www.grai.com/links.htm.
} 
large number of privatization. ${ }^{15}$ In the context of our model bad rating translates into a large $\lambda$. That is, countries characterized by a large $\lambda$ are also countries that get low privatization proceeds. To capture this idea we make the following assumption. ${ }^{16}$

A2

$$
F(\lambda) \in\left[0, F^{*}\right] \text { is a non-increasing and (weakly) convex function of } \lambda \geq 0 \text {. }
$$

Assumption A2 is general enough to capture the outcome of a bargaining game between the government and a private investor that would depend on $\lambda$, or the result of an auction where the number of bidders would be driven by $\lambda$.

\subsection{Regulated monopoly.}

Under public ownership, the government monitors the production of a regulated monopoly ( $R M$ here after). It is accountable for the profits and losses of the firm. This creates a soft-budget constraint (i.e., the public monopoly is always ex-post profitable).

The timing is as follows: The government firstly decides to make the investment $K$. Secondly, nature chooses the marginal $\operatorname{cost} \beta$ according to the distribution function $G(\cdot)$. Thirdly, the regulated firm's manager learns $\beta$, but the government does not. The government proposes a production and transfer scheme $(Q(\cdot), t(\cdot))$. Finally the regulated firm reveals the information $\widehat{\beta}$ and production takes place according to the contract $(Q(\widehat{\beta}), t(\widehat{\beta}))$. We first study the benchmark case of regulation under symmetric information.

\subsubsection{Symmetric information}

When the realization of $\beta$ is publicly observed the government solves $\max _{\{Q, t\}} W$ s.t. $\Pi \geq$ 0 with $W$ and $\Pi$ defined in (5) and (4). Since $\lambda$ is positive, transfers to the regulated firm are costly and must be reduced down to the break-even point $\Pi=0$. That is, $t^{R M *}=-P(Q) Q+K+\beta Q$. Substituting this expression in $W$ and maximizing $W$ with respect to $Q$ yields

$$
Q^{R M *}(\beta)=\frac{1+\lambda}{1+2 \lambda} \frac{a-\beta}{b} .
$$

\footnotetext{
${ }^{15}$ See http://www.ncpa.org/pd/private/oct98ab.html 'Privatization: Privatization Trends in Developing Countries' 1997.

${ }^{16}$ We thank an anonymous referee for suggesting this generalization of the function $F$.
} 
Inserting $Q^{R M *}$ in (5) gives the ex-ante welfare under symmetric information

$$
E W^{R M *}(\lambda)=(1+\lambda)\left(\frac{1+\lambda}{1+2 \lambda} V-K\right)
$$

where $V$ is defined in equation (10). The government invests $K$ in a regulated firm only if (13) is positive. The ex-ante welfare increases in $V$. It is non-monotonic in $\lambda$ if $\frac{1}{2} V>K$. That is, it decreases for small $\lambda$ and increases for large $\lambda$. This deserves a comment.

For small $\lambda$, the government incurs small social costs of transferring money to the regulated firm. It then chooses quantities that are close to the first best level which means a price that is close to marginal cost. Indeed, $\lim _{\lambda \rightarrow 0} Q^{R M *}=(a-\beta) / b$ and therefore $P[(a-\beta) / b]=\beta$. At this price, the regulated monopoly cannot recover its fixed cost. The loss is compensated by a transfer to the firm $t=K>0$. By continuity, the government will subsidize the regulated firm as long as $\lambda$ remains small enough. In contrast, for large $\lambda$, the government is more interested in receiving transfers from the firm than in maximizing consumers surplus. It chooses production to induce a positive profit which is confiscated through taxes. As $\lambda$ becomes very large, the government seeks the maximal revenue from the state-owned firm. In the limit it chooses the production level of a private monopoly (i.e., $\left.\lim _{\lambda \rightarrow \infty} Q^{R M *}=Q^{P M}=(a-\beta) / 2 b\right)$.

\subsubsection{Asymmetric information}

Under asymmetric information, $\beta$ is not observed by the government. The government must design the contracts such that the regulated firm reveals its private information. Incentive compatibility constraints are added to the previous problem. By virtue of the revelation principle, the analysis is restricted to direct truthful revelation mechanism $(\widehat{\beta}=\beta)$. To avoid the technicalities of 'bunching' we make the classical monotone hazard rate assumption:

$$
G(\beta) / g(\beta) \text { is non decreasing. }
$$

We define the virtual cost as

$$
v(\beta, \lambda)=\beta+\frac{\lambda}{1+\lambda} \frac{G(\beta)}{g(\beta)} .
$$


The virtual cost includes the marginal cost of production, $\beta$, and the marginal cost of information acquisition, $\frac{\lambda}{1+\lambda} \frac{G(\beta)}{g(\beta)}$. We deduce that $v(\beta, \lambda) \geq \beta$, and by $\mathrm{A} 3$, that $v(\beta, \lambda)$ increases in $\beta$ and $\lambda$. Let

$$
V^{R M}(\lambda)=\frac{E(a-v(\beta, \lambda))^{2}}{2 b}
$$

This implies that $V^{R M}(\lambda)$ decreases in $\lambda$. Following the Baron-Myerson's (1982) approach, we deduce the following lemma, which proof is standard.

Lemma 1 Under asymmetric information, the optimal production and the ex-ante welfare of a regulated monopoly are those of the symmetric information case evaluated at the virtual cost $v(\beta, \lambda)$. That is,

$$
\begin{gathered}
Q^{R M}(\beta)=Q^{R M *}(v(\beta, \lambda)) \\
E W^{R M}(\lambda)=(1+\lambda)\left(\frac{1+\lambda}{1+2 \lambda} V^{R M}(\lambda)-K\right)
\end{gathered}
$$

The quantity produced by a regulated monopoly under asymmetric information is the quantity of a regulated monopoly under symmetric information valued at the virtual cost. Since $v(\beta, \lambda) \geq \beta$, we deduce that $Q^{R M}(\beta) \leq Q^{R M *}(\beta)$ for any $\beta$. Moreover, since $v(\beta, \lambda)$ increases in $\beta$, the distortion is higher at larger marginal costs. Indeed by lowering the production of inefficient firms, the government reduces the overall incentive to inflate cost report. Comparing (10) and (15) it is easy to verify that $V^{R M}(\lambda) \leq V$ for all $\lambda \geq 0$. Hence, the ex-ante welfare of a regulated monopoly is lower under asymmetric information than under symmetric information: $E W^{R M}(\lambda) \leq W^{R M *}(\lambda)$. In the next section we compare the welfare levels generated by a private monopoly with those of a regulated monopoly.

\subsection{Regulation versus privatization}

As a benchmark case we first consider the symmetric information case.

Proposition 2 Under symmetric information, regulated monopoly dominates privately feasible monopoly, whether the latter is franchised or not. 
Proof: See Appendix 1.

Proposition 2 is very intuitive. Under symmetric information a benevolent government cannot do worse than a private monopoly because, for any realization of $\beta$, it can always replicate the outcome of the private firm. However, it is easy to show that, for large shadow costs of public funds, a regulated monopoly under symmetric information does not bring much more welfare than a private monopoly when the latter pays the maximal franchise fee, $F^{*}$. The welfare function under regulated monopoly then is equal to $E W^{R M *}(\lambda)=$ $((1+\lambda) /(1+2 \lambda)) V / 2+(1+\lambda)(V / 2-K)$, whereas the welfare function under private monopoly is equal to $E W_{F^{*}}^{P M}(\lambda)=V / 4+(1+\lambda)(V / 2-K)$. One can check that the two welfare functions have a common asymptote with slope $V / 2-K$ (see figure 1 ). The welfare of a regulated monopoly coincides with the welfare of a private monopoly for large $\lambda$. From this argument, we can infer that the additional cost introduced by the asymmetry of information in the regulated monopoly gives a welfare advantage to the private monopoly for large $\lambda$. That is, under asymmetric information, the welfare function of the regulated monopoly has an asymptote with (negative or positive) slope $\lim _{\lambda \rightarrow+\infty} E W^{R M}(\lambda) / \lambda=\frac{V^{R M}(\infty)}{2}-K<\frac{V}{2}-K$. Let

$$
R^{\infty} \equiv \frac{V^{R M}(\infty)}{2}-K
$$

We deduce that privately feasible monopolies can dominate regulated monopolies.

Proposition 3 Suppose that assumptions A0 to A3 hold and that a monopoly is privately feasible. Then for $K$ large enough two cases hold: ${ }^{17}$

(i) $\lim _{\lambda \rightarrow+\infty} F(\lambda) \geq R^{\infty}$ : there exists a unique threshold, $\hat{\lambda}$, such that privatization dominates regulation if and only if $\lambda>\hat{\lambda}$.

(ii) $\lim _{\lambda \rightarrow+\infty} F(\lambda)<R^{\infty}$ : there are two thresholds $\hat{\lambda}$ and $\tilde{\lambda}(\hat{\lambda}<\tilde{\lambda})$ such that privatization dominates regulation if and only if $\lambda \in[\widehat{\lambda}, \widetilde{\lambda}]$.

Proof: See Appendix 2.

Figure 1 illustrates Proposition 3. The bold solid curve represents the ex-ante welfare of regulated monopoly under symmetric information $\left(R M^{*}\right)$ and the bold dashed curve

${ }^{17}$ As shown appendix 2 the exact condition is $K \geq V\left(\sqrt{\frac{2 B+V^{R M}(\infty)}{V}}-\frac{1}{2}\right)-B$, with $B=2 \frac{E\left(\frac{G(\beta)}{g(\beta)}(a-\beta)\right)}{2 b}$. 
displays ex-ante welfare under asymmetric information $(R M)$. The ex-ante welfare of regulated monopoly is non-monotone in $\lambda$. It is higher for low or high values of $\lambda$ than for intermediate values. The thin solid lines represent two bounds (i.e., $F(\lambda) \equiv F^{*}$ and $F(\lambda) \equiv 0)$ of ex-ante welfare of a private monopoly $(P M)$. Depending on the franchise fee function, $F(\lambda)$, the welfare function associated to a private monopoly varies between these two bounds.

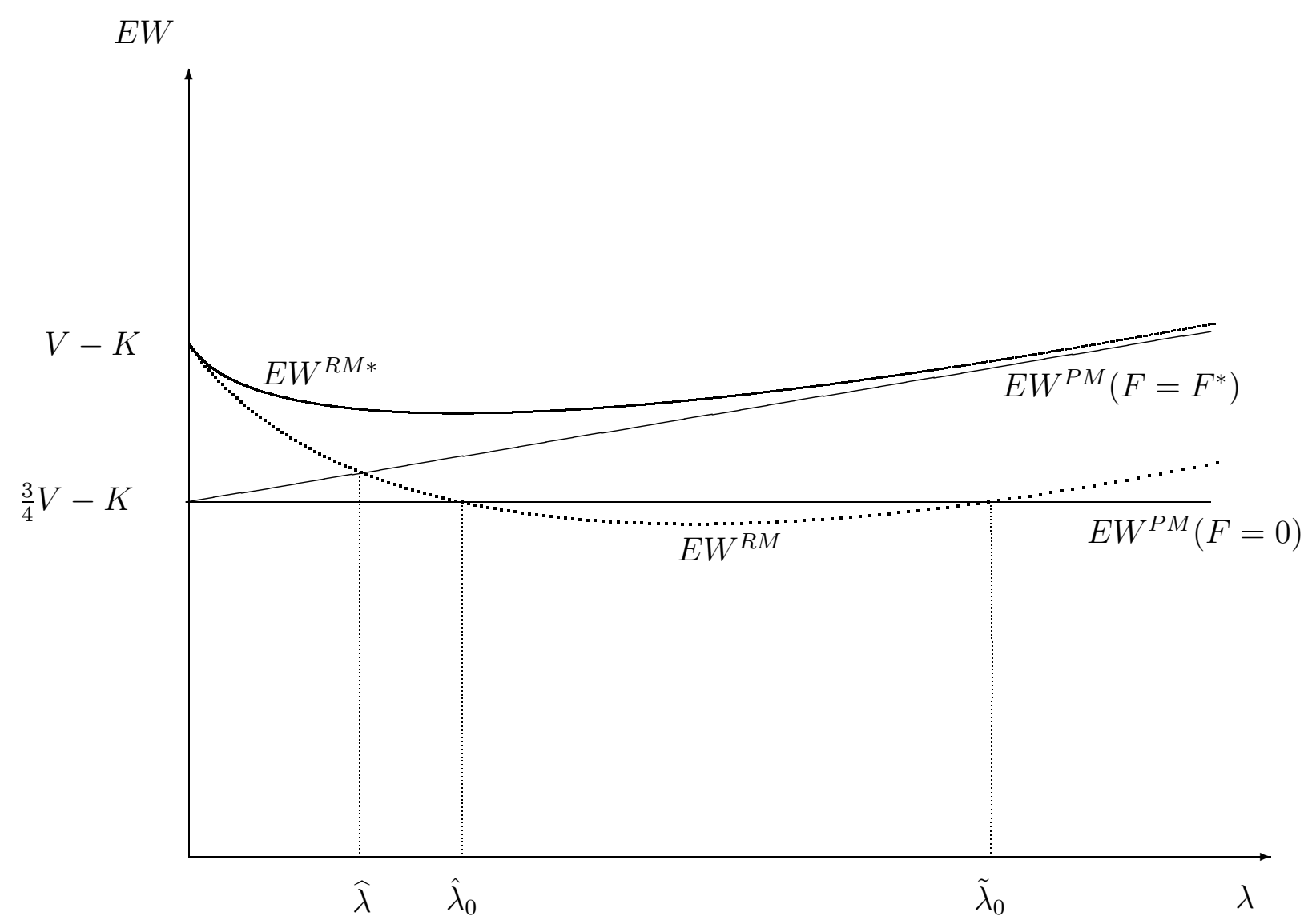

Figure 1: Welfare for Private and Regulated Monopoly

Proposition 3 establishes that privatization under laissez-faire dominates a benevolent regulation under public ownership for (at least) intermediate value of the opportunity cost of the public fund. The result is very robust. As shown appendix 2, under the assumption that $K$ is large enough, which is relevant with natural monopoly, even with $F(\lambda) \equiv 0$, the interval $\left[\widehat{\lambda}_{0}, \widetilde{\lambda}_{0}\right]$ where privatization dominates regulation is non empty (see figure 
1). In other words, positive franchise fee does not explain the preference for private feasible monopolies even if it fosters it. The intuition for this result is as follows. A private entrepreneur enters the business if his/her firm is ex-ante profitable. After the investment, the private firm makes a large or a low operating profit depending on the realization of technical/demand uncertainties. A private entrepreneur, who bets her own assets (or the shareholders' ones) in the firm, is accountable for these profits and losses. In contrast, under regulation, accountability lies on the government side; the business risk is borne by the government that has to grant ex-post subsidies to unprofitable firms. Under symmetric information, the soft-budget constraint plays no role because the government perfectly controls the firm's cost and profit. This is illustrated in figure 1 by the fact that, even for $F(\lambda) \equiv F^{*}, E W^{R M *}(\lambda)$ is always above $E W_{F^{*}}^{P M}(\lambda) \forall \lambda \geq 0$. However, under asymmetric information, the regulated firm uses the soft-budget constraint to acquire a positive informational rent. The government prefers that the private sector takes over when the social cost associated with the rent outweighs the social benefit of controlling the firm's operation. As shown section 5 this ultimately depends on the profitability of the industry.

Positive franchise fee increases the preference for private monopoly. When the franchise fee $F(\lambda)$ is large (i.e., $F(\lambda) \geq R^{\infty} \forall \lambda \geq 0$ ), the shadow costs supporting privatization belong to an unbounded range $[\widehat{\lambda},+\infty)$ (Proposition $3(\mathrm{i})$ ). The optimal industrial policy is monotone in $\lambda$. Regulation is preferred to privatization for $\lambda \leq \hat{\lambda}$, and it is the reverse for $\lambda>\hat{\lambda}$. On the other hand, when the franchise fee falls below the threshold $R^{\infty}$, regulation re-dominates privatization for large value of $\lambda$ (Proposition 3 (ii)). The optimal industrial policy then is non monotone in $\lambda$. For intermediate value of $\lambda$ privatization with price liberalization dominates regulation under public ownership. It is the reverse for lower and larger value of $\lambda$. The intuition for this result is as follow. Governments of developing countries coping with critical budgetary situation are in weak bargaining position in privatization reforms. They let their public assets go at a discount to avoid the embarrassment of unsuccessful sales (see Birdsall-Nellis 2002). In contrast under public ownership they legally seize the firms' profit which provides regular revenue inflows. For instance over the period 1990-95, tax collected from public firms amounted to $8 \%$ of GDP 
in Bolivia, 2.2\% in Brazil, $5 \%$ in Chile, $1 \%$ in India, 3\% in Mexico, $3 \%$ in Peru (World Bank 1998). "On the whole this non-tax revenue is more important for developing than opposed to industrial countries, comprising about 21 percent compared to 10 percent of total revenue." (Burgess and Stern (1993) page 782). We deduce that because of this public convenience governments of developing countries should resist the privatization of their profitable state owned enterprises, which in practice they do. For instance one third of the privatizations to end 1996 in Africa were liquidations or asset sales of unprofitable firms (Sarbib 1997). Similarly Namibia is one of the few countries in the world without privatization plan, mainly because its publics enterprises are operating at a profit (Harsch 2002).

Proposition 3 contrasts with the results obtained in the main strand of the literature on soft-budget constraint (see for instance Schmidt (1996b), Maskin (1999) and Segal (1998)). In this literature, privatization is socially efficient because it avoids the time-inconsistency problem raised by regulation. That is, under regulation the firm anticipates that subsidies to unprofitable firms will be granted since such subsidies are ex-post efficient. Hence, a firm with low profitability prospects will ex-ante deflate its investment level, which is inefficient. Here, the investment $K$ is fixed and common knowledge. The choice between the regulated and the private regime is made before the investment is realized. Therefore, the government is not allowed to take advantage of any investment sunk by the private sector. Still, privatization is socially desirable due to macro-economic considerations.

\subsection{Simulation of $\hat{\lambda}$}

Proposition 3 highlights the unconventional role of the shadow cost of public funds in the government's choice of industrial policy. In particular, whether the firm makes a transfer to the government or not, privatization with prices liberalization dominates a benevolent regulation under public ownership for intermediate value of $\lambda$. The relevance of this result depends on what 'intermediate' value means. If it is very high, in practice privatisation will never be optimal. In what follows we assess the lowest value of the shadow cost, $\hat{\lambda}$, for which privatization becomes attractive. This is by definition when the highest franchise fee $F^{*}$ is applied: $\hat{\lambda}$ solves $E W^{R M}(\lambda)=E W_{F^{*}}^{P M}(\lambda)$ (see figure 1). This equation 
is equivalent to

$$
4(1+\lambda)^{2} V^{R M}(\lambda)=(3+2 \lambda)(1+2 \lambda) V
$$

Using (14) and (15), we observe that this expression defines a second degree equation in $\lambda$. In order to get explicit value for $\hat{\lambda}$, we make the assumption of a uniform distribution of $\beta$ over $[\underline{\beta}, \bar{\beta}]$. Still, the conclusions of the simulation are robust to other statistical specifications (e.g. normal distribution). Under the uniform distribution, equation (19) is equivalent to: $4 E((1+2 \lambda)(a-\beta)-\lambda(a-\beta))^{2}=(3+2 \lambda)(1+2 \lambda) E(a-\beta)^{2}$. We divide the right hand side and the left hand side by $a^{2}$. One can then check that $\hat{\lambda}$ depends on $\beta / a$ and $\bar{\beta} / a$ only. Since under the uniform specification the demand intercept $a$ satisfies A1 if and only if $a \geq 2 \bar{\beta}$, we get that $0 \leq \underline{\beta} / a<\bar{\beta} / a \leq 0.5$. Table 1 displays $\hat{\lambda}$ for the various admissible values of $\underline{\beta} / a$ and $\bar{\beta} / a$.

\begin{tabular}{rr|ccccc}
\hline \hline$\hat{\lambda}$ & & $\underline{\beta} / a=0.0$ & 0.1 & 0.2 & 0.3 & 0.4 \\
\hline \hline $\bar{\beta} / a=0.1$ & 1.14 & - & - & - & - \\
0.2 & 0.71 & 1.07 & - & - & - \\
0.3 & 0.52 & 0.66 & 0.99 & - & - \\
0.4 & 0.42 & 0.48 & 0.60 & 0.90 & - \\
0.5 & 0.35 & 0.38 & 0.44 & 0.54 & 0.81 \\
\hline \hline
\end{tabular}

Table 1: Minimal shadow costs $\hat{\lambda}$ above which privatisation can be preferred

The shadow cost of public funds is generally assessed to be around 0.3 in industrial countries (see for instance Ballard-Shoven-Whalley (1985)) and higher in developing countries. We conclude from the simulation that if demand and cost functions are reasonably approximated by linear functions and satisfy assumption A1, which is an empirical issue, $\hat{\lambda}$ lies in the range of the shadow costs prevailing in developing countries. The results in Table 1 also illuminate that privatisation is more likely as technological uncertainty rises (i.e., $\hat{\lambda}$ decreases with $(\bar{\beta}-\underline{\beta}) / a)$. Indeed larger business uncertainty implies stronger information asymmetry between firms and government and hence larger information cost in the regulated structures. 
We next explore the optimal industrial organization when the fixed cost $K$ becomes smaller or equivalently, when the value of operating the firm after investment, $V$, becomes larger. ${ }^{18}$ This is relevant because in the last two decades some industries such as the telecommunication have experienced dramatic technological and/or demand changes resulting both in a decrease in fixed costs and an increase in demand. Moreover, for a given industry the demand is generally weaker in developing countries than in industrialized countries, resulting in lower $V$. That is, for the same population size, the number of consumers and their propensity to pay are higher in rich countries. This difference might again imply different industrial policy. We study the case of a private duopoly section 4.1, and of a regulated duopoly section 4.2.

\section{Private and regulated duopoly}

\subsection{Private duopoly}

To simplify the exposition we rule out in what follows franchising. The results are nevertheless robust to more favorable specifications of the franchise fee. ${ }^{19}$

$$
F(\lambda) \equiv 0
$$

Private duopoly ( $P D$ here after) is modeled as Cournot duopoly with asymmetric information between firms. Each firm gets private information on its own marginal cost but it is not informed about the competitor's marginal cost. As in any Cournot game, each firm maximizes its profit taking the other firm's output as given. The timing of the game is as follows: First both firms simultaneously make the investments $K$. Second, each firm $i \in\{1,2\}$ learns the realization of its own marginal cost $\beta_{i}$ and chooses its

\footnotetext{
${ }^{18}$ From figure 1, we see that a private monopoly is less likely to be preferred to a regulated monopoly as $K / V$ diminishes. However this result is incomplete. For lower $K / V$ more than one firm may enter the market.

${ }^{19}$ Considering $F>0$ would reinforce the biais in favor of the private monopoly because franchise fees are higher with a monopoly than with a duopoly.
} 
production level $q_{i}$. The equilibrium concept is Bayesian Nash equilibrium:

$$
q_{i}^{*} \in \arg \max _{q_{i}} E_{\beta_{j}}\left[\left(a-b\left(q_{i}+q_{j}^{*}\right)\right) q_{i}-\beta_{i} q_{i}\right] \quad \forall i=1,2, j \neq i
$$

Due to the linear shapes of the demand and cost functions, firm $i$ 's best response strategy is equal to $q_{i}^{*}\left(\beta_{i}\right)=\left(2 a+E \beta-3 \beta_{i}\right) / 6 b{ }^{20}$ The existence of a duopoly with both firms producing at the equilibrium requires that $a \geq(3 \bar{\beta}-E \beta) / 2$, which is true under assumption A1. Substituting $\left(q_{1}^{*}\left(\beta_{1}\right), q_{2}^{*}\left(\beta_{2}\right)\right)$ in (4) and (5), we compute the ex-ante firm profit and the industry welfare of the Cournot duopoly

$$
\begin{aligned}
E \Pi^{P D} & =\frac{2}{9} V+\frac{5}{18} \frac{\sigma^{2}}{2 b}-K, \\
E W^{P D} & =\frac{8}{9} V+\frac{11}{18} \frac{\sigma^{2}}{2 b}-2 K .
\end{aligned}
$$

A duopoly is privately feasible if the two firms are ex-ante profitable. It means that expression (21) should be positive. ${ }^{21}$ A private duopoly is socially desirable if it brings more welfare than a private monopoly. That is, if $E W^{P D} \geq E W^{P M}$. Let $K^{P D / P M}$ be the level of fixed cost such that the government is indifferent between a private duopoly and a private monopoly, i.e. $E W^{P D}=E W^{P M}$. From (9) and (22), we compute

$$
K^{P D / P M}=\frac{5}{36} V+\frac{11}{18} \frac{\sigma^{2}}{2 b}
$$

Walras (1936) and Spence (1976) have shown in a context of symmetric information that industries with increasing returns to scale were characterized by excess entry. The next result shows that the presence of asymmetric information does not alter this result of wasteful competition.

Lemma 4 Under asymmetric information there is excessive entry. Privately feasible duopolies are socially undesirable whenever $\frac{5}{36} V+\frac{11}{18} \frac{\sigma^{2}}{2 b} \leq K \leq \frac{2}{9} V+\frac{5}{18} \frac{\sigma^{2}}{2 b}$.

\footnotetext{
${ }^{20}$ For more on Cournot competition under asymmetric information see Sakai (1985), Shapiro (1986) and Raith (1996).

${ }^{21}$ More generally the expected profit of $N$ firms playing a generalized Cournot competition is $E_{N} \Pi^{i}=$ $\frac{2 V}{(N+1)^{2}}+\frac{(N-1)(N+3)}{2(N+1)^{2}} \frac{\sigma^{2}}{2 b}-K$ with $N \geq 1$. We deduce that if $\frac{V}{8}+\frac{3}{8} \frac{\sigma^{2}}{2 b} \leq K \leq \frac{2 V}{9}+\frac{5}{18} \frac{\sigma^{2}}{2 b}$ then $N \in\{0,1,2\}$. This yields assumption A0.
} 
The set defined by the condition in Lemma 4 is not empty since $\frac{5}{36} V+\frac{11}{18} \frac{\sigma^{2}}{2 b}<\frac{2}{9} V+\frac{5}{18} \frac{\sigma^{2}}{2 b}$ is equivalent to $a>E \beta+\sqrt{3} \sigma$ which is true under A1. Therefore, the ex-ante welfare is higher if a private monopoly is legally set and if entry is prevented. Indeed, firms do not internalize the social cost of the investment duplication in their entry decision. As a result they enter too often in the industry.

\subsection{Regulated duopoly}

Many contributions in procurement and regulation theory emphasize that despite subadditive cost functions, it can be optimal to have several producers in a regulatory setting. A regulated duopoly can be better than a regulated monopoly because it increases the variety of products, lowers transportation costs, or because it reduces prices through (yardstick) competition. In the present model, the firms' marginal cost are independent and identically distributed. The benefit of choosing a regulated duopoly originates from the sampling gain as first analyzed by Auriol and Laffont (1993).

\subsubsection{The sampling effect under symmetric information}

The timing is the same as for a regulated monopoly with the following differences: the investment $K$ is made in the two regulated firms (henceforth $R D$ ) and the marginal cost parameters $\beta_{i}$ with $i \in\{1,2\}$ are independently drawn. Under symmetric information the transfers $t_{i}^{*}$ to the regulated firms $i \in\{1,2\}$ which are socially costly, are reduced until firms break even: $t_{i}^{*}=-(a-b Q) q_{i}+\beta_{i} q_{i}+K$. Substituting this expression into the welfare function yields

$$
W^{R D *}=S(Q)+\lambda P(Q) Q-(1+\lambda)\left(\beta_{1} q_{1}+\beta_{2} q_{2}+2 K\right)
$$

The welfare function is linear in $q_{1}$ and $q_{2}$. Optimizing it with respect to $q_{i}$ we deduce that $q_{i}^{*}=Q^{R D}>0$ if $\beta_{i}=\min \left\{\beta_{1}, \beta_{2}\right\}$ and $q_{i}^{*}=0$ otherwise. The optimal production level coincides with the level of the regulated monopoly defined in equation (12): $Q^{R D *}\left(\beta_{1}, \beta_{2}\right)=Q^{R M *}\left(\min \left\{\beta_{1}, \beta_{2}\right\}\right)$. Monitoring a regulated duopoly is equivalent to monitoring a regulated monopoly for which the investment level is $2 K$ and the marginal 
cost is distributed as $\beta^{\min }=\min \left\{\beta_{1}, \beta_{2}\right\}$, that is, with the law:

$$
g^{\min }(\beta)=2(1-G(\beta)) g(\beta)
$$

The ex-ante welfare of the regulated duopoly under symmetric information is

$$
E W^{R D *}(\lambda)=(1+\lambda)\left(\frac{1+\lambda}{1+2 \lambda} V^{m i n}-2 K\right)
$$

where

$$
V^{m i n}=\int_{\underline{\beta}}^{\bar{\beta}} \frac{(a-\beta)^{2}}{2 b} g^{\text {min }}(\beta) d \beta .
$$

The facts that $g^{\min }(\cdot)$ stochastically dominates $g(\cdot)$ and that $(a-\beta)^{2} / 2 b$ decreases in $\beta$ imply that $V^{\text {min }}>V$. Then comparing (13) and (26), the ex-ante welfare is larger under a regulated duopoly than under a regulated monopoly if the sampling gain, measured by $\left(V^{\min }-V\right)(1+\lambda) /(1+2 \lambda)$, is larger than $K$, the duplicated investment. ${ }^{22}$

\subsubsection{Asymmetric information}

Under asymmetric information, the two regulated firms must be enticed to reveal their private information to the government. By the revelation principle, the analysis is restricted to direct revelation mechanisms. The equilibrium is defined as truthful Bayesian Nash equilibrium. Each firm $i \in\{1,2\}$ sets its revelation strategy $\widehat{\beta}_{i}$ such that it maximizes the expected profit given the cost distribution of the competitor $j \neq i$. Let

$$
V^{R D}(\lambda)=\int_{\underline{\beta}}^{\bar{\beta}} \frac{(a-v(\beta, \lambda))^{2}}{2 b} g^{\min }(\beta) d \beta .
$$

The following lemma presents the structure of production and the welfare level of the duopoly under asymmetric information.

\footnotetext{
${ }^{22}$ Only one firm produces at the equilibrium. This is an artifact of the assumption of constant marginal costs which is used to isolate the sampling effect. Models with non-constant marginal costs yield qualitatively similar results (see Auriol-Laffont 1993). Finally we assume that the government shuts down the least efficient regulated firm for the sake of readability. It could instead transfer the best technology to all regulated firms and share the optimal production $Q^{R D *}$ among them. The analysis would be unaltered.
} 
Lemma 5 Under asymmetric information, only the firm with the lowest marginal cost produces. Output and welfare levels are the levels obtained under symmetric information evaluated at the virtual cost:

$$
\begin{aligned}
Q^{R D}\left(\beta_{1}, \beta_{2}\right) & =Q^{R M}\left(v\left(\beta^{m i n}, \lambda\right)\right) \\
E W^{R D}(\lambda) & =(1+\lambda)\left(\frac{1+\lambda}{1+2 \lambda} V^{R D}(\lambda)-2 K\right) .
\end{aligned}
$$

Proof: The proof is similar as in Auriol-Laffont (1993) Proposition 2.

Monitoring a regulated duopoly is equivalent to monitoring a regulated monopoly for which the investment level is $2 K$, the marginal cost is $v\left(\beta^{\text {min }}, \lambda\right)$ and $\beta^{\text {min }}$ is distributed according to $g^{\min }(\cdot)$. Let $K^{R M / R D}(\lambda)$ be the value of the fixed cost such that the government is indifferent between a regulated monopoly and a regulated duopoly, i.e. such that $E W^{R M}(\lambda)=E W^{R D}(\lambda)$.

$$
K^{R M / R D}(\lambda)=\frac{1+\lambda}{1+2 \lambda}\left(V^{R D}(\lambda)-V^{R M}(\lambda)\right)
$$

Under asymmetric information, the sampling gain is measured by $K^{R M / R D}(\lambda)$. Since the distribution function $g^{\min }(\beta)$ stochastically dominates $g(\beta)$ and since $(a-v(\beta, \lambda))^{2} / 2 b$ decreases in $\beta$ we deduce that $V^{R D}(\lambda) \geq V^{R M}(\lambda)$. However the larger $\lambda$ is, the lower is the impact of the sampling gain and the smaller is the government's preference for regulated duopoly.

\subsection{Private versus regulated duopoly}

We have seen in Section 3 that private monopoly can be preferred to regulated monopoly. By extension, private duopoly could also be preferred to monopoly or regulated duopoly. However, excess entry and weak competition intensity in private duopoly will generally preclude this structure from being socially desirable. To be more specific let $K^{R D / P D}(\lambda)$ be the value of the fixed cost such that regulated duopoly is equivalent to private duopoly, i.e. such that $E W^{R D}(\lambda)=E W^{P D}$. The government prefers a regulated duopoly to a private duopoly if and only if $K \leq K^{R D / P D}(\lambda)$. On the other hand, if $K \geq K^{P D / P M}$ defined in equation (23), the government prefers a private monopoly to a private duopoly. 
We deduce that if

C1

$$
K^{R D / P D}(\lambda) \geq K^{P D / P M}
$$

a private duopoly is never preferred by the government. Appendix 3 shows that assumption $\mathrm{C} 1$ holds if the demand parameter $a$ is not too small. For instance if $\beta_{i}$ is uniformly distributed over $[0, \bar{\beta}]$ then A1 implies $\mathrm{C} 1$.

Lemma 6 Under assumption $\mathrm{C} 1$ a private duopoly is never optimal.

We now turn to the study the optimal industrial policy.

\section{Optimal industrial policy}

Under complete information, the government can always replicate the production decisions of private firms so that privatization is never optimal. The optimal industrial policy varies from no production, regulated monopoly to regulated duopoly according to whether the investment cost $K$ is large, medium or small. Under asymmetric information the softbudget constraint alters this result. That is, let $K^{R M}(\lambda)$ be the value of the fixed cost such that the government is indifferent between a regulated monopoly and no production (i.e. such that $E W^{R M}(\lambda)=0$ ). It is easy to check that

$$
K^{R M}(\lambda)=\frac{1+\lambda}{1+2 \lambda} V^{R M}(\lambda)
$$

Similarly let $K^{R M / P M}(\lambda)$ be the value of the fixed cost such that the government is indifferent between a regulated monopoly and a private monopoly (i.e. such that $E W^{R M}(\lambda)=$ $\left.E W^{P M}\right)$. It is easy to check that

$$
K^{R M / P M}(\lambda)=\frac{(1+\lambda)^{2}}{\lambda(1+2 \lambda)} V^{R M}(\lambda)-\frac{3 V}{4 \lambda} .
$$

We deduce the next result.

Proposition 7 Suppose that assumptions A0 to A4 hold. Under condition C1, the optimal industrial policy under asymmetric information is to set: 
- no production if $K>\max \left\{\frac{V}{2}, K^{R M}(\lambda)\right\}$;

- a private monopoly if $K^{R M / P M}(\lambda)<K \leq \frac{V}{2}$;

- a regulated monopoly if $K^{R M / R D}(\lambda)<K \leq \min \left\{K^{R M / P M}(\lambda), \frac{V}{2}\right\}$ or if $\frac{V}{2} \leq K<$ $K^{R M}(\lambda)$

- a regulated duopoly if $K \leq K^{R M / R D}(\lambda)$.

Proof. See Appendix 4

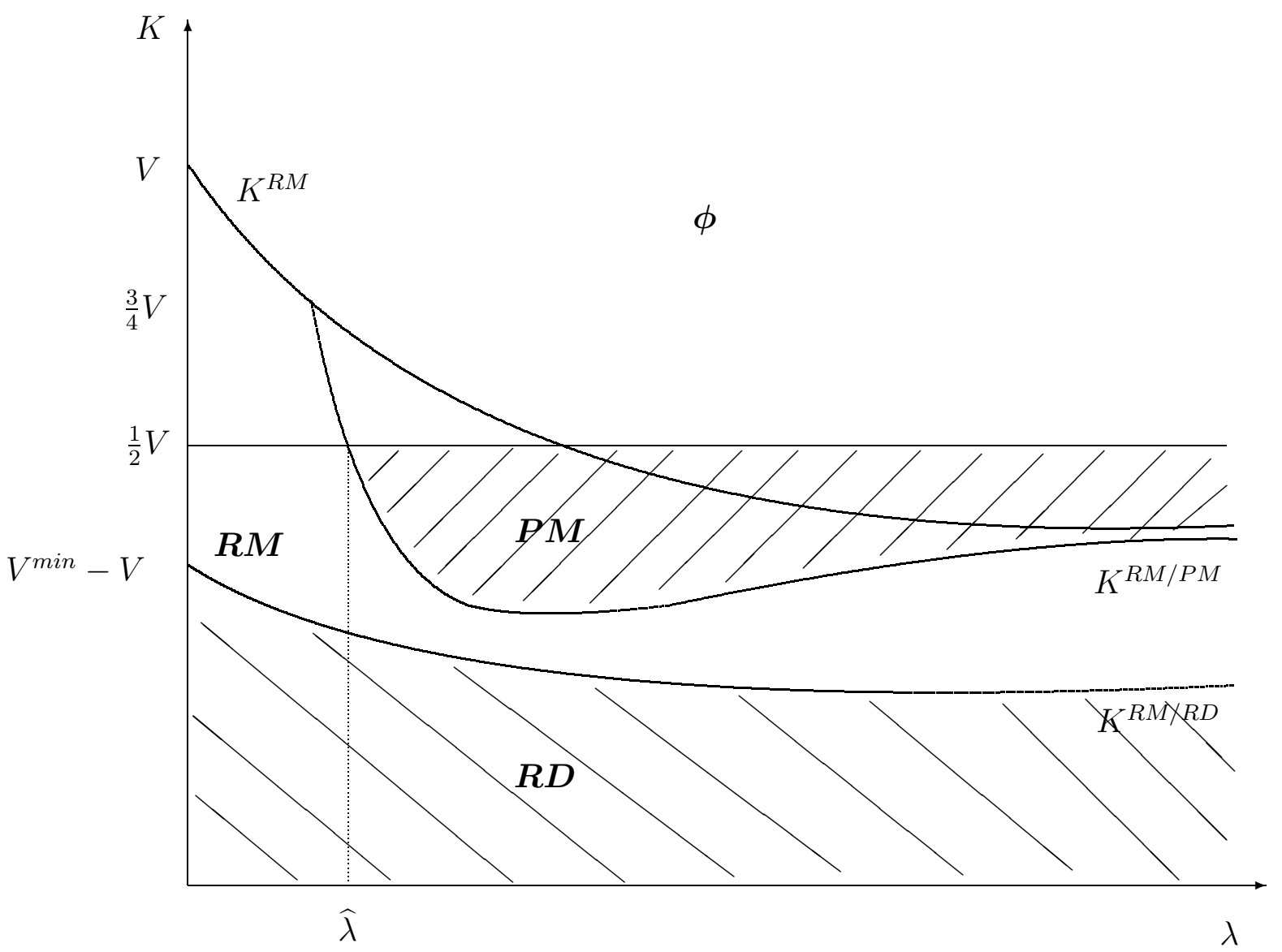

Figure 2: Optimal Industrial Policy

Figure 2 illustrates Proposition 7 in $(\lambda, K)$ space. It allows to consider three types of market organisation for infrastructure and public utilities. 
The first case occurs when the ex-ante profitability of the infrastructure project or of the industry is low (i.e., for $\left.K \geq K^{R M}(+\infty)\right)$. When $K$ is large there is room for at most one firm. The optimal industrial policy then is monotone in the shadow cost of public funds. We distinguish two cases. First when $K$ is larger than $V / 2$ the project is not privately feasible. Depending on $\lambda$ being either low or high the optimal industrial policy is regulation (in wealthy countries) or no production (in poor countries). In figure 2 regulated monopolies that are desirable under asymmetric information are depicted by the white area denoted $R M$, no production corresponds to the area denoted $\emptyset$. Second when $K$ falls below $V / 2$, the project becomes privately feasible for one firm. Regulation is preferred to privatization if $\lambda \leq \hat{\lambda}$ and it is the reverse otherwise. When $K$ is close to $V / 2$ private monopoly is preferred for large $\lambda$ simply because it is feasible whereas regulated monopoly is not. By continuity private monopoly dominates regulated monopoly for lower values of the fixed cost. This situation is denoted $P M$ and is represented by the hatched area above the curve $K^{R M / P M}$.

It is worth noting that under the paper assumptions the critical value $\hat{\lambda}$ lies in the range of the shadow cost of public funds generally retained for developing economies (i.e., $\hat{\lambda} \in[0.35,1.10]) .{ }^{23}$ They may hence implement industrial policies that strongly differ from those implemented in developed economies. Indeed there are a public good aspect and externalities associated to sunk cost investment such as infrastructure (e.g., a road). As recommended by standard economic theory wealthy nations subsidize the construction of the infrastructure and let people use it at marginal cost (e.g., for free). With a low opportunity cost of public funds this policy maximizes welfare. On the other hand many developing countries plagued by financial problems have started build-operate-andtransfer (BOT) programs. In such programs, a private firm finances the sunk cost of an infrastructure, for instance a highway, in exchange for a 10-30 years licence to exploit it in a monopoly position. Clearly, a privately owned and operated infrastructure, even with the monopoly distortion (e.g., a toll), is a better solution than no infrastructure at all, which is, in the absence of public financing, the alternative to privatization. Water

\footnotetext{
${ }^{23}$ The critical value $\widehat{\lambda}$ is the same in figure 1 and 2 . Indeed $\widehat{\lambda}$ in figure 2 is such that $K^{R M / P M}(\lambda)=\frac{V}{2}$. It is easy to check that this equation is equivalent to equation (19).
} 
supply, which typically is provided worldwide through public ownership, could be a good candidate for such type of privatization. This is at least what is advocated by Brook Cowen and Cowen (1998). In developing countries tariffs are so low that on average they do not cover half of the total cost (World Bank 1994). This precludes public investment, and large fraction of the population in cities has no formal water hook-up. To increase access some countries have chosen to implement BOT contracts. China, Malaysia, Thailand implemented it in water, and Chile, Mexico, in sanitation (World Bank 1997). The drawback of such privatization policy is that it increases inequality. That is, rise in public utility tariffs (to reach costs recovery level), recovery of unpaid bills and termination of illegal connexion hurt the poor. On the other hand, extension of the network favor those who are wealthy enough to access the new infrastructure. In their survey on privatization Birdsall-Nellis (2002) hence show that the reforms have worsened wealth and income distribution (see also Estache-Foster-Wodon 2002). This in turn might explain why privatizations are so unpopular. ${ }^{24}$

We believe that privatization is a good alternative to the absence of public funds if it leads to an increase of available infrastructure such as roads, railroads, or distribution networks. Nevertheless the reforms have to be accompanied by subsidies in direction of the poor (either directly from government, or international institutions, or from the wealthy part of the consumers through cross-subsidies) to constitue genuine Pareto improvement. Last, but not least, governments with bad country ratings might find impossible to attract international investors on low profitability projects. They should rather target national private investors or national NGOs which are better informed on local profitability and risk.

The second case occurs when $K$ belongs to $\left[V^{\text {min }}-V, K^{R M}(+\infty)\right]$. When $K$ is lower than $K^{R M}(+\infty)$ the market offer good ex-ante prospects to one firm. Production (with a monopoly) is always optimal. However, contrary to the low profitability case, the optimal industrial policy is non monotone in $\lambda$. This is illustrated Figure 2 by the fact that the

\footnotetext{
${ }^{24}$ For instance $63 \%$ of people surveyed in 2001 in 17 countries of Latin America disagreed or strongly disagreed with the statement "The privatization of state companies has been beneficial" (The Economist July 28-August 3 2001, p38). There is a widespread perception that they have been hurting the poor, notably through increase in tariff and unemployment, while benefiting the powerful and wealthy.
} 
curve denoted $K^{R M / P M}(\lambda)$ is non monotone in $\lambda$. Let $\underline{K}^{R M / P M}$ denote the minimum of $K^{R M / P M}(\lambda)$. For $\underline{K}^{R M / P M} \leq K \leq K^{R M}(+\infty)$, as $\lambda$ increases, the optimal industrial policy successively is regulation, privatization and regulation. Indeed when $\lambda$ is very large the government seeks the maximal revenue from the firm. Privatization which generates low proceeds (because of the high $\lambda$ ) is not appealing. It is better to keep the profitable firm public, while fixing its price close to monopoly level, than to sell it off. This generates more revenue. Prior to the technological boom the telecommunication industry illustrated this non monotonicity result: "A PTT[Post and Telecommunication Company]'s yearly revenues (especially charges from international call) were used by governments to subsidize mail service, or to ease yearly budget deficits. Given this public convenience and necessity, the interests of third world governments are often diametrically opposed to telecom policies of privatization and network deregulation favored by wealthy nations." (Anania 1992).

Finally, when $V / 2$ is much larger than $K$ (i.e., when $K \leq V_{\min }-V$ ), markets offer good ex-ante prospects to more than one firm. Lemma 6 then shows that a private Cournot duopoly is never optimal. The negative impact of market power and excessive entry are too strong compare to the positive effects (here the 'sampling gains') of a regulated duopoly. In other words, the advantage of prices unregulated private structures disappears once the market allows the entry of more than one firm. This result may look at odds with theories where private structures perform better with larger number of entry (see for instance Vickers and Yarrow (1991) and Segal (1998)). A basic difference in our model lies in the intensity of competition that exists within private and regulated structures. Under privatization the firms, which must make a profit to cover their fixed cost, face a Cournot competition. In contrast, under the regulation regime, the information cost drops when a second firm is added in the regulated market. This result is congruent with the theory of adverse selection in which a rise in the number of agents reduces the cost of information revelation (see Auriol \& Laffont (1993)). ${ }^{25}$ The case where regulated duopoly is preferred to regulated monopoly is depicted by the hatched area below the curve $K^{R M / R D}$ denoted

\footnotetext{
${ }^{25}$ If we had considered that firms operating in the same industry have correlated costs, we would have used this correlation to implement yardstick competition, reducing further the cost of information revelation (see Auriol and Laffont 1993).
} 
$R D$

This last result sheds light on the link between market liberalization, on the one hand, and technological and/or product demand changes, on the other hand. Market liberalization, often referred to as 'deregulation', corresponds to the divestiture of the historical monopoly and the introduction of new entrants. As shown Proposition 7 this is not equivalent to laissez-faire. In practice prices and entry remain regulated to protect consumers against collusion and predatory behavior (through licences and price caps for instance). In the framework of our model the divestiture of the historical monopoly is motivated by a drop of the ratio $K / V$. That is, by smaller fixed costs and/or by larger product demand. In figure 2 this corresponds to a downward shift, where industry structure move from regulated monopoly to regulated duopoly.

The telecommunication industry provides an example of such drop. In this industry, the introduction of new technologies has significantly reduced the fixed costs to operate networks whereas the demand for communication has steadily increased. Consistently with our model, many developed and developing countries have deregulated their domestic telecommunication industry. Nevertheless more than 70 percent of all countries still maintain a monopoly in basic services, while more than half allow competition in mobile service (ITU 1999). Wallsten (2000), who studied telecom reforms in Africa and Latin America, found that regulated competition (measured as the number of mobile operators not owned by the incumbent) yields network improvements and that, while privatization by itself does not yield improvements, privatization combined with an independent regulator does. The lesson to be drawn here is that privatization, being defined as a move from regulation to laissez-faire, is not optimal. When the ratio $K / V$ is low, the consumer surplus is large. The industry matters for social welfare and growth. With an oligopolistic structure and potential large rents to make the predatory and collusive behavior of the firms need to be controlled. In practice regulation is a key component of successful liberalization reforms. 


\section{Conclusion}

Considering the government budget constraint, the paper compares utilitarian welfare levels under regulation and privatization in markets characterized by increasing returns to scale. Under public ownership the government which regulates entry and price, is residual claimant for the firm's profit and loss. By contrast, under privatization, the government takes no responsibility for the financial results of the firms. This rules out the problem of soft-budget constraint. The cost is that prices are unregulated.

We show that for investments with low ex-ante profitability (e.g., a road) privatization always dominates regulation for intermediate to large value of the opportunity cost of public funds. Privatization is even Pareto improving when it leads to the creation of an infrastructure that would not have exist otherwise. Simulations suggest that the critical 'intermediate' values compatible with the model assumptions, are in the range of those of developing countries. On the other hand, for profitable natural monopolies (e.g., telecommunication fix distribution network) the optimal industrial policy is non monotone in the shadow cost of public funds. Indeed developing countries plagued with financial problems get bad country risk ratings. They are not able to attract international capital flows so that privatization does not yield large revenue. Since public firms are sold at a discount, government in need for cash should keep the profitable ones. It can then choose monopoly prices and legally capture the profit. We finally show that the advantage of private structures is likely to disappear once the market allows the entry of more than one firm. Technological or demand changes explain the destitution of former regulated monopolies. Smaller fixed costs and larger product demands hence favor markets liberalization which to be successful requires an efficient regulation.

To conclude the optimal industrial policy of a country depends non-trivially on its development stage. We believe these arguments are particularly critical to the LDCs in which due to bad macro-economic conditions and to poorly functioning tax systems governments' budget constraint is extremely tight. 


\section{References}

ANANIA, L. (1992), "The Protean Complex: Are Open Networks Common Markets?", in the Economics of Information Network Ed by C. Antonelli, North-Holland.

AURIOL, E. and J.J. LAFFONT (1993), "Regulation by Duopoly", Journal of Economics and Management Strategy, 3, 507-533.

AURIOL, E. and M. Warlters (2003), "Taxation Base in Developing Countries", forthcoming Journal of Public Economics.

BARON, D. and R. MYERSON (1982), "Regulating a Monopolist with Unknown Costs", Econometrica, 50, 911-930.

BREWER, L.T., and P. RIVOLI (1990), "Politics and Perceived Country Creditworthiness in International Banking", Journal of Money, Credit and Banking, 22(3), 357-369.

BROOK COWEN P. and T. COWEN (1998), "Deregulated Private Water Supply: A Policy Option for Developing Countries", Cato Journal, Vol. 18, No 1, pp 21-41.

DEWATRIPONT M. and MASKIN E. (1995), "Credit and Efficiency in Centralized and Decentralized Economies", Review of Economic Studies, 62(4), pp 541-56.

DANA, J. and K. SPIER (1994), "Designing a Private Industry : Government Auctions with Endogenous Market Structure", Journal of Public Economics, 53, 127-147.

DAVIS, J., OSSOWSKI, R., RICHARDSON, T. and BARNETT, S. (2000), "Fiscal and Macroeconomic Impact of Privatization", I.M.F. Occasional Paper, 194.

ESTACHE A., V. FOSTER, and Q. WODON (2002), "Accounting for Poverty in Infrastructure Reform, Learning from Latin America's Experience", World Bank Institute Development Studies.

Guash, J-L., J-J Laffont, S. Straub (2002), "Renegotiation of Concession Contracts in Latin America", mimeo. IDEI.

GIBBON H. (1998), "Worldwide Economic Orthodoxy", Priv. International, 123, p, 4-5.

GIBBON H. (2000), "Editor's Letter", Privatization Yearbook, London: Thomson Financial, p.1.

HARSCH E. (2002), "Privatization Shifts gears in Africa", Africa Recovery, United Nation. (www.un.org/ecosocdev/geninfo/afrec/vol14no1/privat1.htm) 
KORNAI J. (1979), "Ressource Constraint versus Demand Constraint System", Econometrica, 47, 801-19.

KORNAI J. (1980), "Economics of Shortage", Amsterdam, North-Holland.

KORNAI J. (2001), "Hardening the Budget Constraint: The experience of the postsocialist countries", European Economic Review, 45, p. 1573-99.

LAFFONT, J.J. (2001), "Enforcement, Regulation and Development", mimeo IDEI Toulouse. LAFFONT, J.J. and J. TIROLE (1993), A Theory of Incentives in Procurement and Regulation, MIT press.

LOPEZ DE SILANES, F., SHLEIFER, A. and VISHNY, R., (1997), "Privatization in the United States", Rand Journal of Economics, 28, p. 447-71.

MAHBOOBI L. (2000), "Recent Privatization Trends", OECD, Financial Market Trends, 76 , p. $43-64$.

MASKIN, E. (1999), "Recent Theoretical Work on the Soft Budget Constraint", American Economic Review, 89(2), 421-25.

MEGGINSON W. and NETTER J. (2001), "From State to Market: A Survry of Empirical Studies on Privatization", Journal of Economic Literature, 39, p. 321-89.

NELLIS, J. (1999), "Time to Rethink Privatization In Transition Economies?", International Finance Corporation, Discussion Paper 38.

RAITH M. (1996), "A General Model of Information Sharing in Oligopoly", Journal of Economic Theory, 71(1), pages 260-88.

SAKAI, Y. (1985), "The Value of Information in a Simple Duopoly", J. of Economic Theory, 36(1), 36-54.

SARBIB, J-L. (1997), "Privatization In Africa: Present and Future Trends", African Development Bank Group, 1997 Annual Meeting Symposium on 'Private Sector Development In Africa'.

SCHMIDT, K (1996-a), "The Costs and Benefit of Privatization- An Incomplete Contracts Approach", J. of Law, Economics and Organization, Vol. 12 1-24.

SCHMIDT, K (1996-b), "Incomplete Contracts and Privatization", European Economic Review, Vol. 40 569-580.

SEGAL, I (1998), "Monopoly and Soft Budget Constraint", Rand Journal of Economics, 
29(3), 569-609.

SHAPIRO C. (1986), "Exchange of Cost Information in Oligopoly", Review of Economic Studies, 53(3), p 433-46.

SHAPIRO C. and WILLIG R. (1990), "Economic Rationale for the Scope of Privatization", DP 41, Princeton University.

SNOWER A. and WARREN R. (1996), "The Marginal Welfare Cost of Public Funds: Theory and Estimates", J. of Public Economics, 61, 289-305.

SPENCE M. (1976), "Product Selection, Fixed Costs, and Monopolistic Competition", Review of Economic Studies, 43(2), 217-35.

VICKERS J. and YARROW G. (1991), "Privatization: an Economic Analysis", MIT Press.

WALLSTEN, S. (2000), "An econometric analysis of Telecom Competition, Privatization and Regulation in Africa and Latin America", forthcoming J. of Industrial Economics. WALRAS, L. (1936), "Etudes d'Economie Politique Aplliquée: Théories de la Richesse Sociale", Lausannes F. Rouge.

WORLD BANK (1994), "World Development Report 1994: Infrastructure for Development" New York: Oxford University Press.

WORLD BANK (1997), Toolkits for Private Participation in Water and Sanitation. Washington D.C. World Bank.

WORLD BANK (1998), "World Development Indicators".

\section{Appendix 1: Proof of Proposition 2}

We have to show that $(1+\lambda)\left(\frac{1+\lambda}{1+2 \lambda} V-K\right) \geq \frac{1}{2} V-K+\lambda F(\lambda) \quad \forall \lambda \geq 0$ The maximal franchise fee, denoted $F^{*}$, is equal to the firm's ex-ante profit, i.e. $F^{*}=\frac{1}{2} V-K$. Therefore the above inequality is satisfied if $\forall \lambda \geq 0(1+\lambda)\left(\frac{1+\lambda}{1+2 \lambda} V-K\right) \geq \frac{3}{4} V-K+\lambda\left(\frac{1}{2} V-K\right)$, or equivalently if $4(1+\lambda)^{2} \geq(3+2 \lambda)(1+2 \lambda)$ which is always true $\forall \lambda \geq 0$. 


\section{Appendix 2: Proof of Proposition 3}

Step 1: Regulation is preferred to privatization if and only if $E W^{R M}(\lambda) \geq E W^{P M}(\lambda)$. By virtue of equation (17) this inequality is equivalent to

$$
\frac{(1+\lambda)^{2}}{1+2 \lambda} V^{R M}(\lambda)-(1+\lambda) K \geq \frac{3}{4} V-K+\lambda F(\lambda)
$$

Developing $V^{R M}(\lambda)$ defined equation (15) one can check that:

$$
V^{R M}(\lambda)=\frac{1+2 \lambda}{(1+\lambda)^{2}} V+\frac{\lambda^{2}}{(1+\lambda)^{2}} V^{R M}(\infty)-\frac{\lambda}{(1+\lambda)^{2}} B
$$

where $V=\frac{E\left((a-\beta)^{2}\right)}{2 b}, V^{R M}(\infty)=\frac{E\left(\left(a-\beta-\frac{G(\beta)}{g(\beta)}\right)^{2}\right)}{2 b}$ and $B=2 \frac{E\left(\frac{G(\beta)}{g(\beta)}(a-\beta)\right)}{2 b}$ are all positive by virtue of assumption A1. Substituting (35) in (34) and dividing the right and left hand side by $\lambda$, we get after some straightforward computations:

$$
\frac{V}{4 \lambda} \geq \frac{B}{1+2 \lambda}-\frac{\lambda}{1+2 \lambda} V^{R M}(\infty)+K+F(\lambda)
$$

It is easy to check that the left hand side of (36), denoted $L H S(\lambda)$, is a decreasing and convex function of $\lambda$. Similarly, under the assumption A2 the right hand side of (36), denoted $R H S(\lambda)$, is decreasing and convex.

Step 2: For $\lambda=0,(36)$ is equivalent to $V \geq 0$ which is always true. We deduce that for $\lambda$ small enough regulation dominates privatization.

For $\lambda \rightarrow+\infty$ two cases hold: either $\lim _{\lambda \rightarrow+\infty} L H S(\lambda)>\lim _{\lambda \rightarrow+\infty} R H S(\lambda)$, which is equivalent to $F(+\infty)<R^{\infty}$, or $\lim _{\lambda \rightarrow+\infty} L H S(\lambda) \leq \lim _{\lambda \rightarrow+\infty} R H S(\lambda)$, which is equivalent to $R^{\infty} \leq F(+\infty)$ where $R^{\infty}=\frac{V^{R M}(\infty)}{2}-K$.

Consider first the case $R^{\infty} \leq F(+\infty)$. This condition implies that for $\lambda$ large enough privatization is preferred to regulation. Since it is the reverse for $\lambda$ low enough, and since $L H S(\lambda)$ and $R H S(\lambda)$ are both decreasing and convex in $\lambda$, we deduce that they cross one and only one. This proves part $(i)$ of proposition 3.

Step 3: Consider next the case $R^{\infty}>F(\infty)$. This condition implies that for large enough $\lambda$, regulation is preferred to privatization. Since this is also true for low enough $\lambda$, and since both functions $\operatorname{LHS}(\lambda)$ and $R H S(\lambda)$ are decreasing and convex in $\lambda$, we 
deduce the following possibilities: first, $\operatorname{LHS}(\lambda)$ and $R H S(\lambda)$ never cross, in which case regulation is always preferred to privatization, second, they cross twice which yields part (ii) of proposition 3 .

Step 4: To complete the proof of proposition 3 we need to show that there are at least some values of the parameters such that $\operatorname{LHS}(\lambda)$ and $R H S(\lambda)$ cross twice. Since privatization is less attractive for smaller franchise fees, a sufficient condition is that $L H S(\lambda)$ and $R H S(\lambda)$ crossing twice for $F=0$. By virtue of (34) when $F=0$ privatization is preferred to regulation if and only if $\frac{(1+\lambda)^{2}}{1+2 \lambda} V^{R M}(\lambda)-(1+\lambda) K<\frac{3}{4} V-K$. Substituting $V^{R M}(\lambda)$ defined equation (35) the inequality becomes after some computations

$$
P(\lambda)=\left(V^{R M}(\infty)-2 K\right) \lambda^{2}+(V / 2-B-K) \lambda+V / 4<0 .
$$

Inequality (37) is satisfied for $\lambda \in(\widehat{\lambda}(K), \tilde{\lambda}(K))$ with $0<\widehat{\lambda}(K)<\widetilde{\lambda}(K)$ under three conditions:

(i) $(V / 2-B-K)^{2}>V\left(V^{R M}(\infty)-2 K\right)$.

(ii) $V / 2-B-K<0$

(iii) $V^{R M}(\infty)-2 K>0$

That is, condition (i) yields a positive discriminant for $P(\lambda)=0$ and thus implies the existence of two roots $\hat{\lambda}(K)$ and $\widetilde{\lambda}(K)$; condition (ii) and (iii) imply positivity for both roots of $P(\lambda)=0$; finally since $P(0)>0$ and $\lim _{\lambda \rightarrow+\infty} P(\lambda)>0$ under (iii) we have that $P(\lambda)<0$ for $\lambda \in(\widehat{\lambda}(K), \tilde{\lambda}(K))$.

Note that because $F(\infty) \geq 0$, condition $R^{\infty}>F(\infty)$ assumed under step 3 implies that condition (iii) is always satisfied. Now condition (ii) is satisfied if $\frac{V}{2}-B<K$. We deduce that conditions (ii) and (iii) are satisfied if and only if $K \in\left(\frac{V}{2}-B, \frac{V^{R M}(\infty)}{2}\right)$. This is a non empty set since $V^{R M}(\infty)=V-B+E\left[(G(\beta) / g(\beta))^{2} / 2 b\right]$. Then, observe that the left hand side of condition (i) is equal to zero at $K=\frac{V}{2}-B$ and increases for larger $K$. The right hand side of condition (i) decreases with $K$ and is equal to zero at $K=\frac{V^{R M}(\infty)}{2}$. Hence there exists a unique $\widehat{K} \in\left(\frac{V}{2}-B, \frac{V^{R M}(\infty)}{2}\right)$ such that $(V / 2-B-K)^{2}=V\left(V^{R M}(\infty)-2 K\right)$. Solving this equation one can check that

$$
\widehat{K}=V\left(\sqrt{\frac{2 B+V^{R M}(\infty)}{V}}-\frac{1}{2}\right)-B
$$


To conclude we have just shown that conditions (i), (ii) and (iii) are satisfied for any $K \in\left(\widehat{K}, \frac{V^{R M}(\lambda)}{2}\right)$ which is a non empty set. This complete the proof of proposition 3 . It is independent of the cost distribution.

\section{Appendix 3: Condition C1}

One can check that $K^{R D / P D}(\lambda)=\frac{(1+\lambda)^{2}}{2 \lambda(1+2 \lambda)} V^{R D}(\lambda)-\frac{4}{9} \frac{V}{\lambda}-\frac{11}{9} \frac{\sigma^{2}}{8 b \lambda}$. We deduce that condition $\mathrm{C} 1$ is equivalent after some straightforward computations to

$$
\frac{18(1+\lambda)^{2}}{(1+2 \lambda)(16+5 \lambda)} V^{R D}(\lambda) \geq V+\frac{1+2 \lambda}{16+5 \lambda} \frac{11 \sigma^{2}}{2 b}
$$

Let $v(\beta, \lambda)=\beta+\frac{\lambda}{1+\lambda} \frac{G(\beta)}{g(\beta)}$ be the virtual cost. Simplifying by $2 b, \mathrm{C} 1$ is equivalent to:

$$
\frac{18(1+\lambda)^{2}}{(1+2 \lambda)(16+5 \lambda)} E_{\beta^{\min }}\left[(a-v(\beta, \lambda))^{2}\right] \geq E_{\beta}\left[(a-\beta)^{2}\right]+\frac{(1+2 \lambda) 11 \sigma^{2}}{16+5 \lambda} .
$$

Let $h(\lambda)=\frac{18(1+\lambda)^{2}}{(1+2 \lambda)(16+5 \lambda)}-1=\frac{2-\lambda+8 \lambda^{2}}{(1+2 \lambda)(16+5 \lambda)}>0 \forall \lambda \geq 0$.

Let $\Phi(\lambda)=E_{\beta^{\min }}\left[v(\beta, \lambda)^{2}\right]+\frac{E_{\beta^{\min }}\left[\left(v(\beta, \lambda)^{2}\right]-E_{\beta}\left[\beta^{2}\right]\right.}{h(\lambda)}-\frac{(1+2 \lambda) 11 \sigma^{2}}{(16+5 \lambda) h(\lambda)}$.

Let $\Gamma(\lambda)=E_{\beta_{\text {min }}}[v(\beta, \lambda)]+\frac{E_{\beta_{\min }}[v(\beta, \lambda)]-E \beta}{h(\lambda)}$.

Condition $\mathrm{C} 1$ then is equivalent to:

$$
a^{2}-a 2 \Gamma(\lambda)+\Phi(\lambda) \geq 0
$$

Note first that if $\Gamma(\lambda) \leq 0$ and $\Phi(\lambda) \geq 0$ then condition (41) is always true. Similarly if $\Gamma(\lambda)^{2} \leq \Phi(\lambda)$ condition (41) is always true. We consider next $\Gamma(\lambda)^{2}>\Phi(\lambda)$. In this case condition (41) is true if $a$ is larger than $a^{l}$.

$$
a^{l}=\operatorname{Max}\left\{\Gamma(\lambda)+\sqrt{\Gamma(\lambda)^{2}-\Phi(\lambda)} ; \Gamma(\lambda)-\sqrt{\Gamma(\lambda)^{2}-\Phi(\lambda)}\right\}
$$

In other words condition (41) requires that $a$ is large enough. The condition is not very strong. For instance, for a uniform distribution, C1 is always true under assumption A1. That is, with an uniform distribution over $[0, \bar{\beta}]$, and with the convention that $a=A \bar{\beta}$, condition $\mathrm{C} 1$ is equivalent after some computation to: $H(A)=12 A^{2}\left(8 \lambda^{2}-\right.$ $\lambda+2)+12 A(4-7 \lambda)(1+2 \lambda)+(1+2 \lambda)(44 \lambda-59) \geq 0$. Under the assumption A1 (i.e., $A \geq 2$ ), it is easy to check that $H(A)$ is increasing in $A$ for all $\lambda \geq 0$. We deduce that $H(A) \geq H(2)=136 \lambda^{2}-98 \lambda+133>0 \forall \lambda \geq 0$. 


\section{Appendix 4: Proof of Proposition 7}

First of all recall that $K^{R M / R D}(\lambda)$, defined equation (31), is the value of the fixed cost such that the government is indifferent between a regulated monopoly and a regulated duopoly (i.e. such that $E W^{R M}(\lambda)=E W^{R D}(\lambda)$ ). A regulated monopoly is preferred to a regulated duopoly if and only if $K \geq K^{R M / R D}(\lambda)$ defined equation (31). Similarly a regulated monopoly is preferred to no production whenever $K \leq K^{R M}(\lambda)$, defined equation (32). It is preferred to privatisation whenever $K \leq K^{R M / P M}(\lambda)$, defined equation (33). Comparing equations (32) and (33) one can check that $K^{R M}(\lambda)>K^{R M / P M}(\lambda)$. Moreover using the fact that $g^{\min }(\beta) \leq 2 g(\beta)$, one can check that $V^{R D}(\lambda)<2 V^{R M}(\lambda)$ so that $K^{R M}(\lambda)>K^{R M / R D}(\lambda)$. We deduce that if $K>K^{R M}(\lambda)$ regulation is never optimal. On the other hand if $K>\frac{V}{2}$ privatisation is not possible. Putting all the pieces together yields the result.

\section{Acknowledgement}

Pierre Picard's work has been supported by a grant "Actions de Recherche Concertées" $n^{\circ}$ 93/98-162 of the Ministry of Scientific Research of the Belgian French Speaking Community. We are grateful to Amir R. and Michael Warlters for improvements of the paper. Any remaining errors are our own. 